\title{
New proposed method for traceability dissemination of capacitance measurements
}

\author{
Heba A. M. Hamed, A. Eliwa Gad, M. Helmy A. Raouf \\ Department of Electrical Quantities Metrology, National Institute of Standards (NIS), Egypt
}

\section{Article Info}

Article history:

Received Aug 26, 2020

Revised Dec 22, 2020

Accepted Jan 5, 2021

\section{Keywords:}

Capacitance measurements

Metrology

Traceability dissemination

Uncertainty budget

\begin{abstract}
Capacitance measurements at the National Institute of Standards (NIS), Egypt, are traceable to the Bureau International des Poids et Mesures (BIPM). It calibrates the main NIS standard capacitors, AH11A. In this paper, traceability of the BIPM capacitance measurements could be used to evaluate a new accurate measurement method through an Ultra-Precision Capacitance Bridge. The new method is carefully described by introducing some necessary equations and a demonstrating chart. Verification of this new method has been realized by comparing its results for the $10 \mathrm{pF}$ and $100 \mathrm{pF}$ capacitance standards with the results obtained by the conventional substitution method at $1 \mathrm{kHz}$ and $1.592 \mathrm{kHz}$. The relative differences between the two methods are about $0.3 \mu \mathrm{F} / \mathrm{F}$, which reflect the accuracy of the new measurement method. For higher capacitance ranges, the new measurement method has been applied for the capacitance measurements up to $1 \mu \mathrm{F}$ at $1 \mathrm{kHz}$. The relative differences between the two methods are in the range of $5.5 \mu \mathrm{F} / \mathrm{F}$ on the average which proves the acceptable accuracy and the reliability of the new method to be used.
\end{abstract}

This is an open access article under the CC BY-SA license.

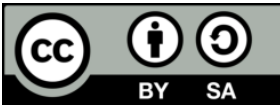

Corresponding Author:

Heba A. M. Hamed

Department of Electrical Quantities Metrology

National Institute of Standards (NIS)

Mohamed Anwer El-Sadat (Tersa) Street, El Haram, El Giza, Egypt

P.O.Box: 136 Giza, Code No: 12211

Email: Heba_ahmed_mohamed@yahoo.com

\section{INTRODUCTION}

Reference values of the capacitance standards are primarily determined in terms of the quantized Hall resistances using a quadrature bridge through some consecutive measurements [1-6]. They are carried out for different capacitance standards at different frequencies [7-13]. Accurate dissemination of the capacitance unit in a wide range of the measurement is a very important issue in the calibration laboratories. Therefore, traceability chains of the capacitance measurements are established for different accuracy levels to develop capacitance scaling systems. However, it is difficult to construct a very accurate capacitance scaling system due to the lack of perfect linearity commercial instruments. So, there are some limitations on the capacitance range and the operation frequency range for any capacitance scaling system. One of these systems was mainly constructed by a commercially available four-terminal-pair LCR meter and an inductive voltage divider (IVD) [14]. Generally, the LCR meter is used as a transfer device with minimum linearity errors [15]. The IVD and the LCR meter can be calibrated by comparing two calibrated 4TP air capacitors with known frequency dependence [16, 17]. Therefore, a capacitance scaling system is established by using different components, and it should be evaluated and verified [18].

Capacitance measurements at the National Institute of Standards (NIS), Egypt, are mainly traceable to the Bureau International des Poids et Mesures (BIPM). It calibrates three of the NIS standard capacitors, Fused Silica capacitors model AH11A, which have capacitance standard values of $1 \mathrm{pF}, 10 \mathrm{pF}$, and $100 \mathrm{pF}$. For higher capacitance ranges, the NIS measurements are traceable to the National Physical Laboratory (NPL) which is the National Metrology Institute (NMI) of UK. 
A Bilateral comparison between the NIS and the BIPM was carried out from November 2015 to March 2016. Two $10 \mathrm{pF}$ and two $100 \mathrm{pF}$ traveling standards belonging to the BIPM were measured at $1592 \mathrm{~Hz}$ and $1000 \mathrm{~Hz}$, with a maximum uncertainty of $0.7 \mathrm{ppm}$, using a coverage factor $\mathrm{k}=2$, for the NIS measurements were obtained by a direct substitution method. [19]. The NIS measurement results were obtained using AH 2700A - Opt. E \& Opt. C, Ultra-precision Capacitance Bridge [20, 21].

In this paper, a new accurate method has been introduced for disseminating the traceability of the capacitance measurements over a wide range. This method depends on applying the correction factor obtained at $20 \%$ of the value to be calibrated to compute its actual value from its measured value. Full demonstration of this new calibration method has been presented in detail. Starting from the $1 \mathrm{pF}$ capacitance standard value that is calibrated at the BIPM, the actual values of the proceeding standards up to $1 \mu \mathrm{F}$ could be determined at $1 \mathrm{kHz}$ with their associated expanded uncertainties using the new measurement method. Validation of this new accurate method up to $100 \mathrm{pF}$ range has been obtained by comparing its results with the results obtained by the originally used substitution method at $1 \mathrm{kHz}$ and $1.592 \mathrm{kHz}$ through the BIPM traceability. Whereas the validation of the new accurate method for higher ranges up to $1 \mu \mathrm{F}$ at $1 \mathrm{kHz}$ has been obtained by the same comparison but through the NPL traceability. All measurements have been carried out using our Ultra-Precision Capacitance Bridge, which is the newest product of the Andeen-Hagerling Corporation. Most of the NMIs, including NIS, take a capacitance value at $1 \mathrm{kHz}$ frequency as standard value for capacitance calibrations. So, many researches are carried out to improve the capacitance measuremtns and uncertainty at different frequencies [22, 23]. The uncertainty calculations of the NIS capacitance measurements are carried out according to the international statements [24-26], and the expanded uncertainties are computed for $95.54 \%$ confidence level at a coverage factor $\mathrm{k}=2$.

\section{METHODOLOGY OF THE NEW ACCURATE METHOD}

The new method based on having two calibrated capacitance standards of the same value at every range. The method proves that applying the correction factor obtained at $20 \%$ level of the value to be calibrated to compute its actual value can be performed with a good level of accuracy. Firstly, we should have two calibrated equal standard capacitances, $C_{X_{1}}=C_{X_{2}}$, which their parallel measured value, $C_{2 X_{m}}$, is equal to $20 \%$ of the standard capacitance to be calibrated $C_{Y}$, where:

$$
C_{Y}=10 C_{X_{1}}
$$

Accordingly, $C_{2 X_{m}}$ can be measured, using a suitable capacitance measuring device, and expressed as given in (2).

$$
C_{2 X_{m}}=C_{X_{1}}+C_{X_{2}}
$$

Then the corresponding computed value, $C_{2 X_{C}}$, for the reference values of the two capacitances, $C_{X_{1 R}}$ and $C_{X_{2 R}}$ obtained from the calibration certificates, can be computed using (3).

$$
C_{2 X_{C}}=C_{X_{1 R}}+C_{X_{2 R}}
$$

Therefore, the deviation between the measured and the computed values, $D_{20 \%}$, is determined as stated in (4).

$$
D_{20 \%}=C_{2 X_{m}}-C_{2 X_{c}}-D_{\mathrm{S}}
$$

This deviation, $D_{20 \%}$, represents the deviation in the measurement device at the value of $20 \%$ of the standard capacitance to be calibrated, and it is used to determine the actual value, $C_{Y_{2}}$, of the measured value, $C_{Y_{2 m}}$, of the standard capacitance to be calibrated, $C_{Y}$, as presented in (5). The drift in the used standards, $D_{S}$, should be taken into consideration while determining $D_{2 X}$. $D_{S}$, represents the deviation of the measured value of the two calibrated standard capacitors from their calibration certificates. It can be neglected by performing the measurements in a relatively short period which is very close and near to the standards calibration. In this case, the measured values of the standards can be directly compared to certified values without any required drift corrections. Therefore, $D_{20 \%}$, represents the deviation due to the measurement device only. Nevertheless, the per year standards drift should be also taken into consideration during the uncertainty estimations. Two examples are demonstrated in detail below to present the uncertainty components for low and high capacitance values.

$$
\grave{Y_{Y_{2}}}=C_{Y_{2 m}}-D_{20 \%}
$$


Then the actual value of the standard capacitance that is required to be calibrated $C_{Y_{2}}$ is obtained by using the deviation, $D_{Y_{1}}$, determined by substitution method through a reference certified value of another standard capacitance, $C_{Y_{1 R}}$, having the same value of the capacitance to be calibrated. Its measured value, $C_{Y_{1 m}}$, obtained by the same measuring device as described in (6) and (7).

$$
\begin{aligned}
& D_{Y_{1}}=C_{Y_{1 m}}-C_{Y_{1 R}} \\
& C_{Y_{2}}=C_{Y_{2 m}}-D_{Y_{1}}
\end{aligned}
$$

To verify this new method, the obtained value, $\overline{C_{Y_{2}}}$ from the $20 \%$ deviation is compared to the obtained actual value, $C_{Y_{2}}$, form the substitutional method, to specify the relative accuracy, A, of the new method as given in $(8)$.

$$
A=\left(\grave{C}_{Y_{2}}-C_{Y_{2}}\right) / C_{Y}
$$

\section{PRACTICAL CONFIRMATION OF THE NEW ACCURATE METHOD}

NIS has two sets of the AH11A capacitance standards that have capacitance values of $1 \mathrm{pF}, 10 \mathrm{pF}$, and $100 \mathrm{pF}$. The first set is calibrated at the BIPM, as mentioned before, and it is used through the substitution method to calibrate the second set. The NIS capability to use the substitution method has perfectly checked through the pre-described bilateral comparison with the BIPM. To validate the new introduced calibration method, the actual values of the $10 \mathrm{pF}$ and $100 \mathrm{pF}$, of the second standards set, have been determined also by using the new method and the results are compared to those obtained by the substitution method. Therefore, in the new method, the two $1 \mathrm{pF}$ capacitance standards are used to calibrate the $10 \mathrm{pF}$. Then, the two $10 \mathrm{pF}$ calibrated standard capacitors are used to determine the actual value of the $100 \mathrm{pF}$ as, for example, demonstrated in the chart depicted in Figure 1. The correction factor obtained at the $20-\mathrm{pF}$ value is applied to the measured value of the $100 \mathrm{pF}$ to compute its actual value, which is compared to that obtained by the conventionally used substitution method as demonstrated in Figure 1. All measurements in this paper have been carried out using an Ultra-Precision Capacitance Bridge "AH2700A Option-C+E Multi-Freq. Capacitance/Loss Bridge", shown in Figure 2. It has specific Gold-Plated Low Noise Coaxial Cables and connections, AH-DCOAX-TPG1-BNC.

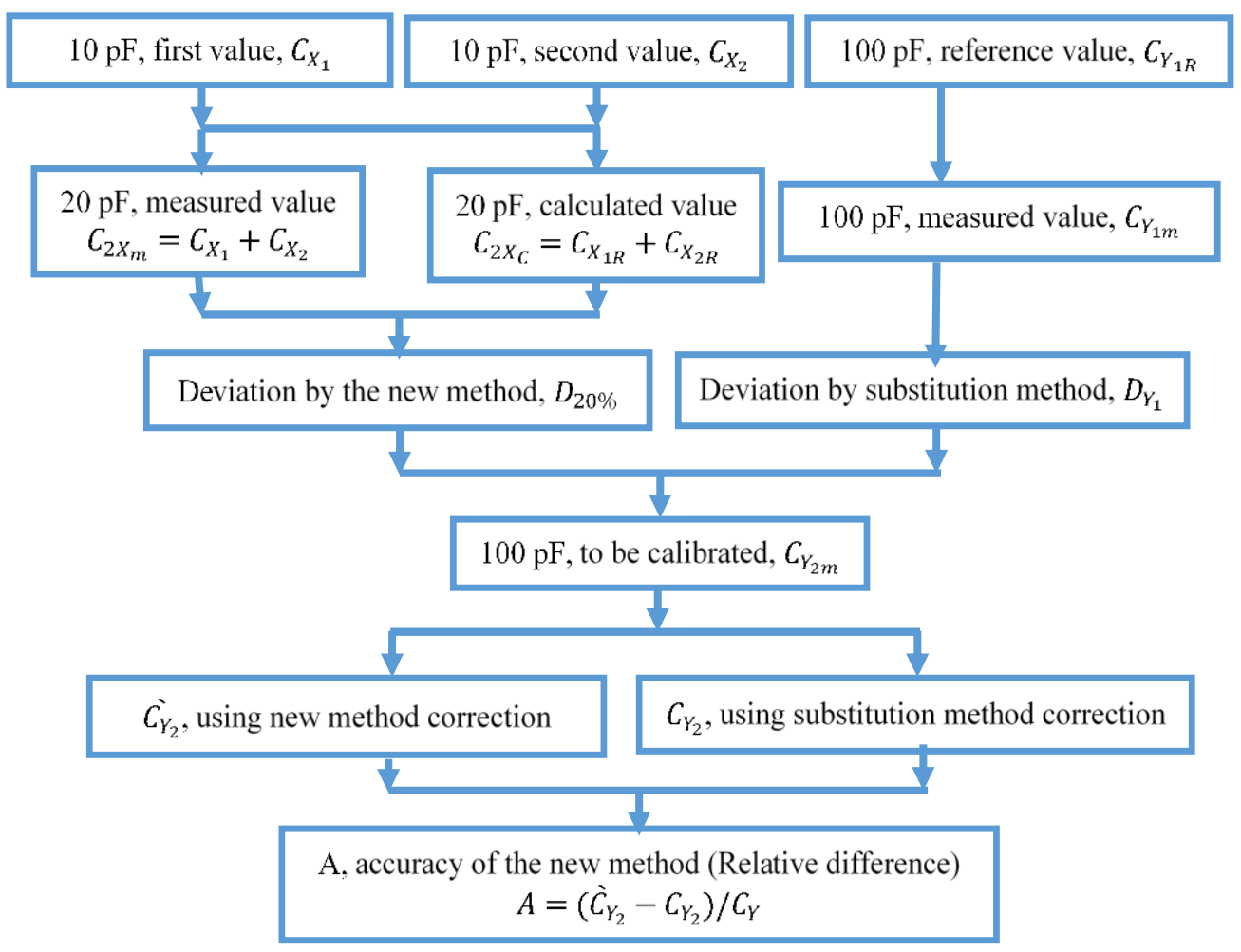

Figure 1. Chart for confirmation of the new accurate method 


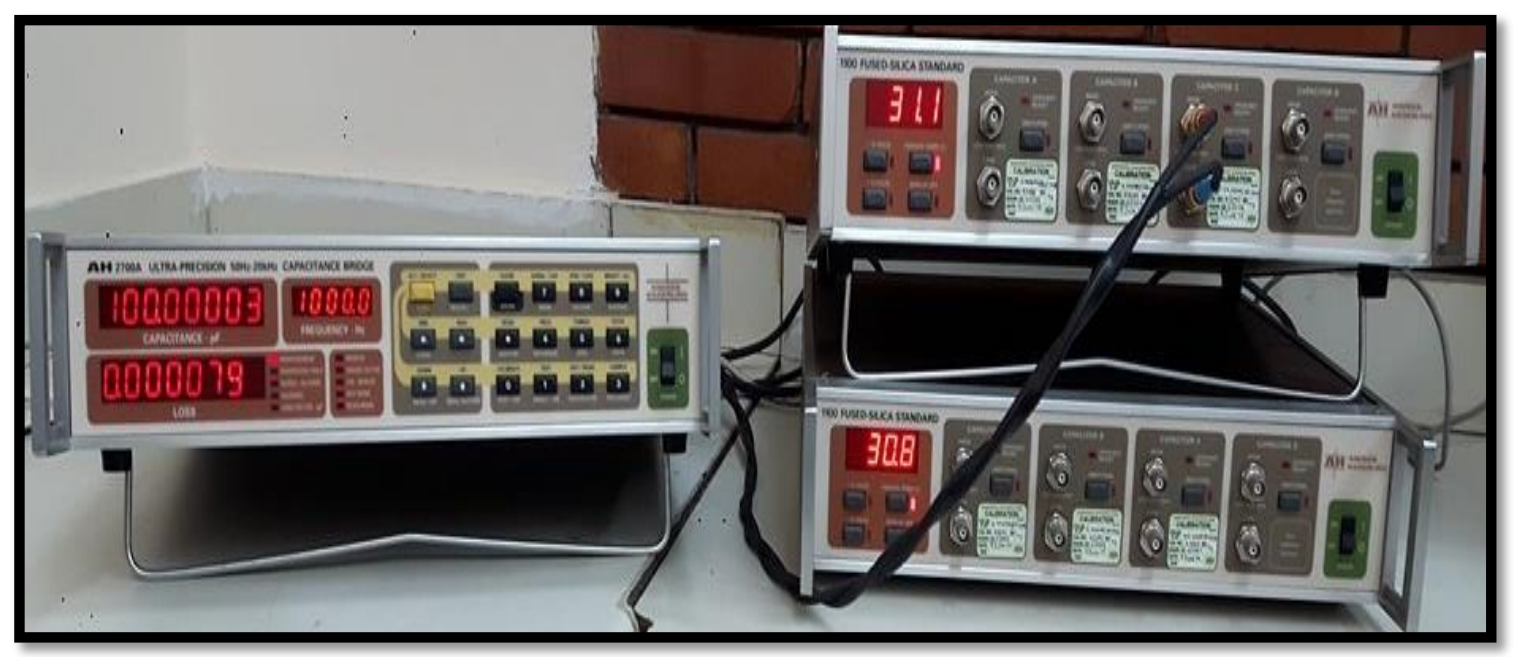

Figure 2. NIS capacitance measurement system formed by the latest AH bridge and the two highly accurate capacitance standards sets

\section{RESULTS AND DISCUSSIONS}

The new proposed calibration method has been experimentally implemented at electrical quantities metrology laboratory, NIS, EGYPT. The traceability of the lower values capacitance standards has been disseminated to higher capacitance values as well be investigated in the following sub-sections.

\subsection{Confirmation of the new accurate method}

The new proposed calibration method has been applied, at NIS, by using the previously described method to calibrate the capacitance of $10 \mathrm{pF}$ and $100 \mathrm{pF}$ values at $1 \mathrm{kHz}$ and $1.592 \mathrm{kHz}$. The results obtained by the two methods, new proposed method and conventional substitution method, are compared to validate the proposed method. The differences between them where found to be about $0.3 \mu \mathrm{F} / \mathrm{F}$ as listed in Table 1 . The obtained $0.3 \mu \mathrm{F} / \mathrm{F}$ accuracy level result proves that the new proposed calibration method is accurate and can be reliably used to disseminate the measurement traceability in such low capacitance values.

Table 1. Relative differences between the new accurate calibration method and the conventional substitution method using the BIPM traceability

\begin{tabular}{ccc}
\hline Nominal Value & $\begin{array}{c}\text { A, relative accuracy using the } \\
\text { BIPM traceability at } 1 \mathrm{kHz},(\mu \mathrm{F} / \mathrm{F})\end{array}$ & $\begin{array}{c}\text { A, relative accuracy using the BIPM } \\
\text { traceability at } 1.592 \mathrm{kHz},(\mu \mathrm{F} / \mathrm{F})\end{array}$ \\
\hline $10 \mathrm{pF}$ & 0.289 & 0.288 \\
$100 \mathrm{pF}$ & 0.305 & 0.281 \\
\hline
\end{tabular}

\subsection{Confirmation of the new accurate method at higher capacitance values}

The new validated calibration method has been applied, at NIS, by using the previously described method to calibrate the capacitance ranges up to $1 \mu \mathrm{F}$ at $1 \mathrm{kHz}$. Firstly, the parallel value of the two $1 \mathrm{pF}$ calibrated standard capacitors, capacitance value of $2 \mathrm{pF}$, are used to calibrate two capacitance standards each has a capacitance value of $10 \mathrm{pF}$. Subsequently, the recently calibrated capacitance value of $20 \mathrm{pF}$, two parallel $10 \mathrm{pF}$, is used to calibrate two capacitance standards each has a capacitance value of $100 \mathrm{pF}$. The obtained actual values of the used $10 \mathrm{pF}$ and $100 \mathrm{pF}$ capacitance standards at $1 \mathrm{kHz}$ are shown in Table 2 with their relative expanded uncertainty. The approximated relative difference between the new accurate calibration method and the conventional substitution method using the BIPM traceability is written in Table 2 on the average for the clarity.

Table 2. Calibration of the NIS capacitance standards up to $100 \mathrm{pF}$ at $1 \mathrm{kHz}$ using the new accurate confirmed method

\begin{tabular}{cccc}
\hline Nominal Value & $\begin{array}{c}\text { Actual Value, New } \\
\text { Method }\end{array}$ & $\begin{array}{c}\text { A, relative accuracy using the } \\
\text { BIPM traceability at } 1 \mathrm{kHz},(\mu \mathrm{F} / \mathrm{F})\end{array}$ & $\begin{array}{c}\text { Relative uncertainty } \\
(\mu \mathrm{F} / \mathrm{F}), \mathrm{k}=2\end{array}$ \\
\hline $10 \mathrm{pF}$ & $9.9999985 \mathrm{pF}$ & 0.297 (on the average) & 0.68 \\
$100 \mathrm{pF}$ & $100.00002 \mathrm{pF}$ & & 0.70 \\
\hline
\end{tabular}


Consequently, the calibrated capacitance standard value of the $200 \mathrm{pF}$ is used to calibrate capacitance values of $1 \mathrm{nF}$. And so on by repeating the same procedure of the new calibration method at higher values, then the actual values of other NIS capacitance standards, $10 \mathrm{nF}, 100 \mathrm{nF}$ and $1 \mu \mathrm{F}$, could be obtained and presented in Table 3 with their related uncertainties. Above $100 \mathrm{pF}$, our standards are calibrated at the National Physical Laboratory (NPL), the NMI of the UK, which is the NIS traceability source for these ranges. Therefore, the linearity of the bridge at such higher capacitance values could be also verified by comparing the actual values obtained by the new method with those obtained by the conventional substitution method using the NPL traceability. The relative difference between the two methods is in the range of $5.5 \mu \mathrm{F} / \mathrm{F}$ on the average which reflects the acceptable accuracy and the reliability of the new method to be used also for such higher capacitance ranges as shown in Table 3.

Table 3. Calibration of the NIS capacitance standards above $100 \mathrm{pF}$ at $1 \mathrm{kHz}$ using the new accurate confirmed method

\begin{tabular}{cccc}
\hline Nominal Value & $\begin{array}{c}\text { Actual Value, New } \\
\text { Method }\end{array}$ & $\begin{array}{c}\text { A, relative accuracy using the NPL } \\
\text { traceability at } 1 \mathrm{kHz},(\mu \mathrm{F} / \mathrm{F})\end{array}$ & $\begin{array}{c}\text { Relative uncertainty } \\
(\mu \mathrm{F} / \mathrm{F}), \mathrm{k}=2\end{array}$ \\
\hline $1 \mathrm{nF}$ & $1.0000222 \mathrm{nF}$ & & 0.83 \\
$10 \mathrm{nF}$ & $9.9840598 \mathrm{nF}$ & $5.5 \mu \mathrm{F} / \mathrm{F}$ (on the average) & 1.13 \\
$100 \mathrm{nF}$ & $100.10557 \mathrm{nF}$ & & 1.20 \\
$1 \mu \mathrm{F}$ & $1.001797 \mu \mathrm{F}$ & 4.36 \\
\hline
\end{tabular}

The uncertainty budget of the $100 \mathrm{pF}$ and $1 \mu \mathrm{F}$ measurements are introduced in Table 4 , as examples for the details of the computed uncertainty values given in Tables 1 and 2. The effect of the cables when connecting two capacitors in parallel has been evaluated for all cases, and it could be neglected for capacitance values up to $1 \mathrm{nF}$. Above that value, the cables effect does not exceed $3.7 \mathrm{ppm}$ on the average. Uncertainty evaluation for the cables effect contribution has been taken into consideration in the uncertainty budget as shown in Table 4

It can be noticed that the uncertainty of the $1 \mu \mathrm{F}$ value is relatively high due to its high repeatability value and cables effect, while the uncertainties of the other capacitance values are relatively small. They are comparable to the uncertainties obtained using the substitution method during the BIPM bilateral comparison which were about $0.7 \mu \mathrm{F} / \mathrm{F}$ as previously mentioned.

\begin{tabular}{|c|c|c|c|}
\hline Source of Uncertainty & Distribution/Type & $\begin{array}{l}\text { Relative uncertainty } \\
(\mu \mathrm{F} / \mathrm{F}) \text {, for } 100 \mathrm{pF}\end{array}$ & $\begin{array}{l}\text { Relative uncertainty } \\
(\mu \mathrm{F} / \mathrm{F}) \text {, for } 1 \mu \mathrm{F}\end{array}$ \\
\hline Repeatability & Normal / A & 0.001 & 2.076 \\
\hline $\begin{array}{l}\text { Capacitance standard certificate } \\
\text { (including cables effect) }\end{array}$ & Normal / B & 0.090 & 0.470 \\
\hline Bridge resolution & Rectangular / B & 0.003 & 0.288 \\
\hline Drift of the used standard & Rectangular / B & 0.110 & 0.173 \\
\hline Stability of the bridge & Rectangular / B & 0.290 & 0.289 \\
\hline Temp. stability of the bridge & Rectangular / B & 0.003 & 0.003 \\
\hline Nonlinearity of the bridge & Rectangular / B & 0.130 & 0.127 \\
\hline \multicolumn{2}{|c|}{ Combined uncertainty } & 0.348 & 2.177 \\
\hline \multicolumn{2}{|c|}{ Expanded uncertainty $(\mathrm{k}=2)$} & 0.696 & 4.355 \\
\hline
\end{tabular}

\section{CONCLUSION}

The new calibration method has been verified by comparing its results for the $10 \mathrm{pF}$ and $100 \mathrm{pF}$ capacitance values with the results of the conventional substitution method using the BIPM traceability for the same values at $1 \mathrm{kHz}$ and $1.592 \mathrm{kHz}$. The accuracy of the new calibration method is about $0.3 \mu \mathrm{F} / \mathrm{F}$ in these low ranges. For higher capacitance ranges, the new method has been verified by comparing its results with those obtained by the conventional substitution method using the NPL traceability. In this case, the relative difference between these two methods is in the range of $5.5 \mu \mathrm{F} / \mathrm{F}$ on the average.

The obtained results prove that the introduced new calibration method is accurate and can be reliably used to disseminate the measurement traceability over a wide range up to $1 \mu \mathrm{F}$ with acceptable uncertainties. It colud be also recommended that the new calibration method should be used in calibration laboratories that don't have sufficient standards to cover all ranges required to calibrate capacitance meters using the conventional method. 


\section{REFERENCES}

[1] L. Callegaro, V. D'Elia, and B. Trinchera, "Realization of the farad from the de quantum Hall effect with digitally assisted impedance bridges," Metologia, vol.47, pp. 464-472, 2010.

[2] A. D. Inglis, B. M. Wood, M. Côté, R. B. Young, and M. D. Early, "Direct Determination of Capacitance Standards Using a Quadrature Bridge and a Pair of Quantized Hall Resistors," IEEE Trans. Instrum. Meas., vol. 52, no. 2, pp. 559-562, Apr. 2003.

[3] J. Schurr, V. B"urkel, and B. P. Kibble, "Realizing the farad from two ac quantum Hall resistances," Metrologia, vol. 46, pp. 619-628, 2009.

[4] S. W. Chua, B. P. Kibble, and A. Hartland, "Comparison of Capacitance with AC Quantized Hall Resistance," IEEE Trans. Instrum. Meas., vol. 48, no. 2, pp. 342-345, Apr. 1999.

[5] D. B. Kim, Dewi M. Kassim, Wan-Seop Kim, L. Callegaro, Vincenzo D’Elia, B. Trinchera, J. Kučera, and R. Sedláček, "Traceability chain at KRISS from DC quantum Hall resistance to Farad using Coaxial Bridges," IEEE Transactions on Instrumentation and Measurement, vol. 68, no. 6, pp. 1941-1947, June 2019.

[6] Ngoc Thanh Mai Tran, Wan-Seop Kim, and D. B. Kim, "Calibration of $10 \mathrm{nF}$ Capacitance Standard from dc QHR using a Digital Imedance Bridge," Precision Electromagnetic Measurements (CPEM) 2020 Conference on, pp. 1-2, 2020.

[7] Y. Nakamura, M. Nakanishi, and T. Endo, "Measurement of Frequency Dependence of Standard Capacitors Based on the QHR in the Range between $1 \mathrm{kHz}$ and $1.592 \mathrm{kHz}$," IEEE Trans. Instrum. Meas., vol. 50, no. 2, pp. 290-293, Apr. 2001.

[8] M. Helmy A. Raouf, "Completely Automated System for Capacitance Measurement through New Accurate Capacitance Box", International Journal of Metrology and Quality Engineering, vol. 8, no. 22, pp. 1-8, October 2017.

[9] F. Delahaye and R. Goebel, "Evaluation of the Frequency Dependence of the Resistance and Capacitance Standards in the BIPM Quadrature Bridge," IEEE Trans. Instrum. Meas., vol. 54, no. 2, pp. 533-537, Apr. 2005.

[10] S. A. Awan and B. P. Kibble, "Towards Accurate Measurement of the Frequency Dependence of Capacitance and Resistance Standards up to $10 \mathrm{MHz}, 2004$ Conference on Precision Electromagnetic Measurements, London, 2004, pp. 41-42.

[11] M. Helmy A. Raouf, Kyu-Tae Kim, and Mun-Seog Kim, "Measurement of Capacitance and Resistance Using Two Perfectly Synchronized Voltage Sources", Measurement, vol. 60, pp. 174-177, January 2015.

[12] M. Helmy A. Raouf, "Manual / Automated Capacitance Box Using Micro - Controller Technique", MAPANJournal of Metrology Society of India, vol. 26, no. 2, pp. 105-113, June 2011.

[13] A. B. Kotb, Ibrahim M. H. Saad, F. M. El-Lithy, and M. Helmy A. Raouf, "A New Proposed Design for Capacitance Measuring Bridge", Journal of Al-Azhar University Engineering Sector, JAUES, vol. 2, no. 5, pp. 3947, April 2007.

[14] T. Aoki and K. Yokoi, "Capacitance Scaling System,” IEEE Trans. Instrum. Meas., vol. 46, no. 2, pp. 474-476, Apr. 1997.

[15] K. Suzuki, A. Yamazaki, and K. Yokoi, "Non-Linearity Evaluation Method of Four-Terminal-Pair (4TP) LCR Meter," in Proc. NCSL Int. Workshop Meas., Washington, DC, Jun. 2001.

[16] S. Zamurovic, A. Koffman, N. Oldham, and B. Waltrip, "The sensitivity of a method to predict a capacitor's frequency characteristics," IEEE Trans. Instrum. Meas., vol. 49, no. 2, pp. 398-404, Apr. 2000.

[17] A. Koffman, S. Zamurovic, B. Waltrip, and N. Oldham, "Uncertainty analysis for four-terminal-pair capacitance and dissipation factor characterization at $1 \mathrm{MHz}$ and $10 \mathrm{MHz}$," IEEE Trans. Instrum. Meas., vol. 49, no. 2, pp. 346348, Apr. 2000.

[18] S. Zamurovic, A. Koffman, B. Waltrip, and Y. Wang, "Evaluation of a Capacitance Scaling System," IEEE Trans. Instrum. Meas., vol. 56, no. 6, pp. 2160-2163, Dec. 2007.

[19] P. Gournay, M. Helmy A. Raouf, Heba A. M. Hamed, and A. Eliwa Gad, "Bilateral comparison of $10 \mathrm{pF}$ and 100 pF standards (ongoing BIPM key comparisons BIPM.EM-K14.a and 14.b) between the NIS (Egypt) and the BIPM," Metrologia, vol. 54, Tech. Suppl. 01008, 2017.

[20] “2700A 50Hz-20kHz Ultra-Precision Capacitance Bridge Operation and maintenance manual”, Ver. 2, 2018

[21] AH 2700A - Opt. E \& Opt. C, Ultra-precision Capacitance Bridge, available: [Online] http://www.andeenhagerling.com/ah2700a.htm.

[22] A. M. Jeffery and A. D. Koffman, "Improved 1-kHz Capacitance Calibration Uncertainty," IEEE Trans. Instrum. Meas., vol. 52, no. 4, pp. 1284-1288, Aug. 2003.

[23] Wang, Yicheng and Shields, Scott., "Improved Capacitance Measurements with Respect to a 1-pF Cross-Capacitor From 200 to 2000 Hz," IEEE Trans. Instrum. Meas., vol. 54, no. 2, pp. 542 - 545, May 2005.

[24] "Evaluation of Measurement Data-Guide to the Expression of Uncertainty in Measurement," JCGM 100:2008; BIPM, IEC, IFCC, ILAC, ISO, IUPAC, IUPAP and OIML, Edition 1, (September 2008), Corrected Version 2010.

[25] "The Expression of Uncertainty and Confidence in Measurement," United Kingdom Accreditation Service (UKAS), M 3003 Edition 3, November 2012.

[26] "Expression of the Uncertainty of measurement in Calibration," European co-operation for Accreditation (EA), rev02, 2013. 


\section{BIOGRAPHIES OF AUTHORS}

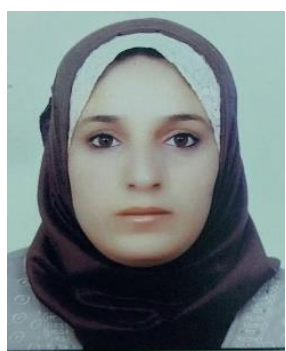

Heba Ahmed Mohamed Hamed, received the B. Sc. and the M. Sc., in Electrical Power and Machine from the Faculty of Engineering, Ain Shams University, Cairo, Egypt in July 2004 and February 2013 respectively, received the Ph.D., in Electrical Engineering from the Faculty of Engineering, Al-Azhar University, Cairo, Egypt in April 2019. She joined the National Institute of Standards (NIS), Egypt, in 2005. In 2019 she became Researcher at the National Institute of Standards (NIS).

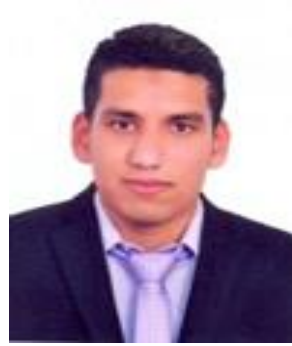

Ahmed Eliwa Abdo Gad, received the B. Sc. and the M. Sc., in Electronics and communications Engineering from the Faculty of Engineering, El Shorouk Academy and AlAzhar University, Cairo, Egypt in May 2008 and February 2016 respectively. He joined the National Institute of Standards (NIS), Egypt, in 2010. In 2016 he became Assistant Researcher at the National Institute of Standards (NIS).

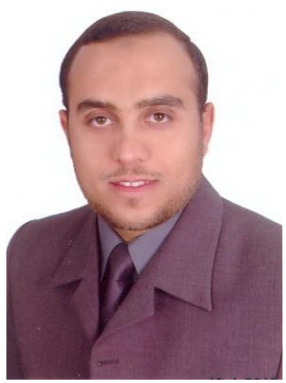

Mohammed Helmy Abd El-Raouf, received the B. Sc., the M. Sc., and the Ph. D. in Electrical Engineering from the Faculty of Engineering, Al-Azhar University, Cairo, Egypt in May 2001, January 2005 and 2007, respectively. In 2018 he became full Professor. He joined the National Institute of Standards (NIS), Egypt, in 2003. From 4/2010 to 4/2011 he was Post - Doctor at Korea Research Institute of Standards and Science (KRISS), Deajeon, South Korea. Since 2013, he has been a Head of Department of the Electrical Quantities Metrology at NIS. Since 2016, he is the vice chair, of the Technical Committee for Electricity and Magnetism (TC-EM) of AFRIMETS, the intra-Africa metrology system, and the Egyptian delegate to the Consultative Committee for Electricity and Magnetism (CCEM) of the International Committee for Weights and Measures (CIPM). His research interests are mainly in the electrical machines and metrology of the electrical quantities such as capacitance, inductance, resistance, impedance and AC-DC measurements. He published about 40 papers in refereed scientific journals and has 6 patents. He teaches some courses in electrical engineering. 